\title{
Noninvasive positive pressure ventilation in subjects with stable COPD: a randomized trial
}

This article was published in the following Dove Press journal:

International Journal of COPD

2I November 2013

Number of times this article has been viewed

Surya $\mathrm{P}$ Bhatt ${ }^{\prime}$

Michael W Peterson ${ }^{2}$

Jeffrey SWilson'

Lakshmi Durairaj'

'Division of Pulmonary, Critical Care, and Occupational Medicine, Department of Internal Medicine, Roy J and Lucille A, Carver College of Medicine, University of lowa Hospital, lowa City, IA, USA; ${ }^{2}$ Department of Medicine, UCSF Fresno Medical Education Program, Fresno, CA, USA
Correspondence: Lakshmi Durairaj Division of Pulmonary, Critical Care, and Occupational Medicine,

Department of Internal Medicine, Roy J and Lucille A, Carver College of Medicine, University of lowa Hospital, lowa City, IA 52242, USA

$\mathrm{Tel}+\mathrm{I} 3193562653$

Fax +I 3193536406

Email lakshmi-durairaj@uiowa.edu
Background: The use of domiciliary noninvasive positive pressure ventilation (NPPV) in stable chronic obstructive pulmonary disease (COPD) with chronic hypercapnic respiratory failure has yielded variable effects on survival, quality of life, and dyspnea. We hypothesized that use of NPPV in stable COPD and partial pressure of carbon dioxide $\left(\mathrm{PaCO}_{2}\right)<52 \mathrm{mmHg}$ might result in improvement in quality of life and dyspnea.

Methods: Thirty patients with stable COPD (forced expiratory volume in the first second $<50 \%$ predicted and $\mathrm{PaCO}_{2}<52 \mathrm{mmHg}$ ) were prospectively randomized to receive domiciliary NPPV (bilevel positive airway pressure, $15 / 5 \mathrm{~cm} \mathrm{H}_{2} \mathrm{O}$ ) or usual therapy for 6 months. Measurements were made at baseline, 6 weeks, 3 months, and 6 months. Primary outcomes were quality of life as assessed by the Chronic Respiratory Disease Questionnaire (CRQ), and dyspnea as measured by the Transitional Dyspnea Index (TDI).

Results: Fifteen subjects in the NPPV arm and 12 controls completed all the study visits. At 6 weeks and 3 months, the NPPV arm showed significant improvement in TDI total score. However, this effect persisted only in the TDI-Task at 6 months $(P=0.03)$. NPPV use was associated with a small improvement in the CRQ-Mastery domain ( 0.6 versus $-0.1, P=0.04)$. The arterial partial pressure of oxygen $\left(\mathrm{PaO}_{2}\right)$ in the control arm worsened over the period of the study, whereas it remained stable in the NPPV arm (change $-7.2 \mathrm{mmHg}$ versus $+2.1 \mathrm{mmHg}$, respectively, $P=0.02$ ).

Conclusion: NPPV resulted in a small improvement in quality of life indices in stable COPD patients with $\mathrm{PaCO}_{2}<52 \mathrm{mmHg}$. Future larger studies will clarify the role of NPPV in this stable subgroup of patients with COPD.

Keywords: noninvasive, ventilation, chronic obstructive pulmonary disease, normocapnia

\section{Introduction}

Chronic obstructive pulmonary disease (COPD) is associated with a progressive decline in lung function and resultant chronic respiratory failure. This leads to significant rates of hospitalization, disability, and death. ${ }^{1}$ COPD is also associated with sleep-disordered breathing and nocturnal hypoventilation, resulting in nocturnal and daytime hypoxemia and hypercapnia., ${ }^{2,3}$ These, in turn, can contribute to fatigue, dyspnea, and impaired quality of life. Nocturnal noninvasive positive pressure ventilation (NPPV) can theoretically rest overloaded respiratory muscles, prevent nocturnal hypoventilation, and reset central respiratory drive in patients with hypercapnia. The use of NPPV in late-stage COPD appears logical to change this inexorable course, to alleviate symptoms, and to improve quality of life. While NPPV has a definite role in the management of acute hypercapnic respiratory failure, ${ }^{4}$ its role in the management 
of late-stage stable COPD is controversial. Multiple studies have shown no survival benefit for nocturnal NPPV in chronic stable hypercapnic COPD patients..$^{5-10}$ The effects on quality of life and dyspnea scores in such patients have been inconsistent. ${ }^{8-11}$ The variable efficacy might have been due to late administration of the intervention in the course of disease, in the presence of advanced hypercapnic respiratory failure. We sought to assess the effect of applying NPPV on indices of health-related quality of life in patients with relative normocapnia. We hypothesized that patients with stable severe COPD and partial pressure of carbon dioxide $\left(\mathrm{PaCO}_{2}\right)<52 \mathrm{mmHg}$ have improved quality of life and reduced dyspnea with the use of NPPV.

\section{Materials and methods}

We conducted a prospective, randomized controlled study. ${ }^{12}$ Subjects were screened from the pulmonary clinic at the University of Iowa Hospital. The protocol was approved by the institutional review board (20010044) and informed consent was obtained from each subject.

\section{Patients}

Subjects with stable COPD, defined as a forced expiratory volume in the first second $\left(\mathrm{FEV}_{1}\right)$ /forced vital capacity (FVC) ratio of $<0.70$, with at least a 10 pack-year smoking history and $\mathrm{PaCO}_{2}<52 \mathrm{mmHg}$ were eligible. ${ }^{13}$ Stable COPD was defined as no exacerbations in the 4 weeks prior to initiation of the study. Only patients with a low clinical probability of having obstructive sleep apnea as assessed using the Berlin Questionnaire were included. This was done to remove the possible confounding effect of sleep apnea. ${ }^{14}$ Those with diagnoses of congestive heart failure, obstructive sleep apnea, chronic respiratory conditions other than COPD, age $<35$ years, any disease limiting life expectancy to less than 2 years, active malignancy other than nonmelanotic skin cancer in the previous 2 years, and with any anatomic variation or disease process that precluded wearing a nasal mask were excluded. Subjects could be active or ex smokers, but had to have a stable smoking status for at least 6 months prior to study initiation. Patients could also have undergone pulmonary rehabilitation or be in a maintenance program, but they could not initiate a pulmonary rehabilitation program during the 6-month observation period.

Subjects were randomized to receive or not receive domiciliary NPPV at $15 / 5 \mathrm{~cm} \mathrm{H}_{2} \mathrm{O}$. Subjects were randomized in a 1:1 ratio to receive NPPV versus control treatment using a random number generator. Randomization was done using opaque sealed envelopes which were opened during screening visits. For this study, we defined hypercapnia as $\geq 52 \mathrm{mmHg}$ based on the criteria used for reimbursement for noninvasive ventilation by the Centers for Medicare and Medicaid Services. ${ }^{15}$ Once subjects were randomized to the NPPV arm, they were initiated on NPPV at home by a respiratory therapist. Subjects were fitted with a nasal-oral contour comfort gel full face mask (Respironics Inc, Murrysville, PA, USA) or nasal pillows (Nellcor Puritan-Bennett Inc, Pleasanton, CA, USA) as needed for optimal comfort and minimal leak. NPPV was initiated at home using a BiPAP ${ }^{\circledR}$ Synchrony ventilator (Respironics Inc) and titrated to final pressures of $15 / 5 \mathrm{~cm} \mathrm{H}_{2} \mathrm{O}$ within a week. Subjects were instructed to use the ventilator all night or for at least 6 hours every night for the next 6 months. Respiratory therapists called the subjects every day during the first week to ensure optimal usage and to troubleshoot any complications. The therapists also made a home visit to check the use of domiciliary NPPV periodically during the first week and as needed thereafter. All subjects were provided with heated humidification.

A complete history and physical examination was undertaken, with a posterolateral chest radiograph, 12-lead electrocardiogram, lung physiology (spirometry, arterial blood gases on room air), and respiratory muscle strength (negative inspiratory force $[\mathrm{NIF}]$ ) at baseline. We measured exercise capacity by the six-minute walk test. ${ }^{16}$ Dyspnea was assessed using the Baseline Dyspnea Index and the Transitional Dyspnea Index (TDI). ${ }^{17}$ We included a global assessment of health-related quality of life developed for patients with chronic lung disease, ie, the Chronic Respiratory Disease Questionnaire (CRQ). ${ }^{18}$ Sleep quality was assessed using the Pittsburgh Sleep Quality Index. ${ }^{19}$ Subjects were reassessed at 6 weeks, 3 months, and 6 months after randomization. The primary outcome was change in the CRQ domains and change in TDI. The minimal clinically important difference in CRQ was defined as a change in the score by 0.5 units, ${ }^{18}$ and that in TDI by one unit. ${ }^{17}$ Secondary outcomes were change in NIF, arterial partial pressure of oxygen $\left(\mathrm{PaO}_{2}\right)$, $\mathrm{FEV}_{1}$, and six-minute walk test. Ventilator use data were downloaded using Encore software (Respironics Inc) at each follow-up visit.

\section{Side effects and compliance}

At each visit, subjects on NPPV were asked about side effects, such as dryness of eyes, sinus congestion, skin abrasions, and epistaxis. Compliance was assessed by both patient-reported hours of use at each visit and machine-downloaded data for 
hours of use. Data obtained from the machine were used for analyses.

\section{Statistical analysis}

Results are expressed as the mean (standard deviation) for normally distributed data and median with interquartile range for nonuniformly distributed data. The baseline characteristics of subjects in the NPPV and control arms were compared using the Student's $t$-test for continuous variables and the Mann-Whitney $U$ test as appropriate, and the chi-square test for categorical variables. Differences within groups at the end of 6 months were compared with baseline using the paired $t$-test and between groups using the independent $t$-test. Repeated-measures analysis of variance was used to assess significant changes over time, and the independent $t$-test was used to assess where any change occurred between groups.

Distribution of data was assessed using Mauchly's test of sphericity, and Greenhouse-Geisser correction was used where sphericity could not be assumed. Relationships between outcomes and change from baseline to 6 months in variables that could affect outcomes were assessed using Spearman's correlation. A $P$-value $<0.05$ was considered to be statistically significant. Multivariate analyses for outcomes after adjusting for baseline $\mathrm{PaCO}_{2}$ and NIF were done and showed no change in the results, and hence are not reported. We did not make any sample size justification because this was a pilot study in relatively normocapnic subjects. All analyses were performed using Statistical Package for the Social Sciences version 11.5 software (SPSS Inc., Chicago, IL, USA).

\section{Results}

Thirty subjects with COPD were recruited. Twenty-seven completed all assessments, ie, 15 in the NPPV group and 12 in the control group (Figure 1). The baseline characteristics of subjects who were able to complete the study are shown in Table 1. There were a higher proportion of males in the control group. The two groups were well matched for age, body mass index, disease severity, and baseline indices of dyspnea, functional capacity, quality of life, and sleep indices. At 6 weeks and 3 months, NPPV resulted in a significant improvement in TDI in the NPPV arm (data in Figure 2, Table S1). However, this effect persisted only in the TDI-Task at 6 months $(-0.8$ versus $-1.8, P=0.03)$. Table 2 shows the effects of NPPV at the end of 6 months. NPPV did not result in improvement in global quality of life as assessed by the total CRQ score. Subjects using NPPV did experience a small improvement in the mastery domain of the CRQ, a difference in the realm of being clinically significant ( 0.6 versus $-0.1, P=0.04$, Figure 2 ). When assessed by repeated measures over time, only the improvement in the mastery domain of CRQ was sustained (data in Table S1).

The oxygenation status of controls worsened over the period of the study $(-7.2 \mathrm{mmHg})$, whereas NPPV resulted in

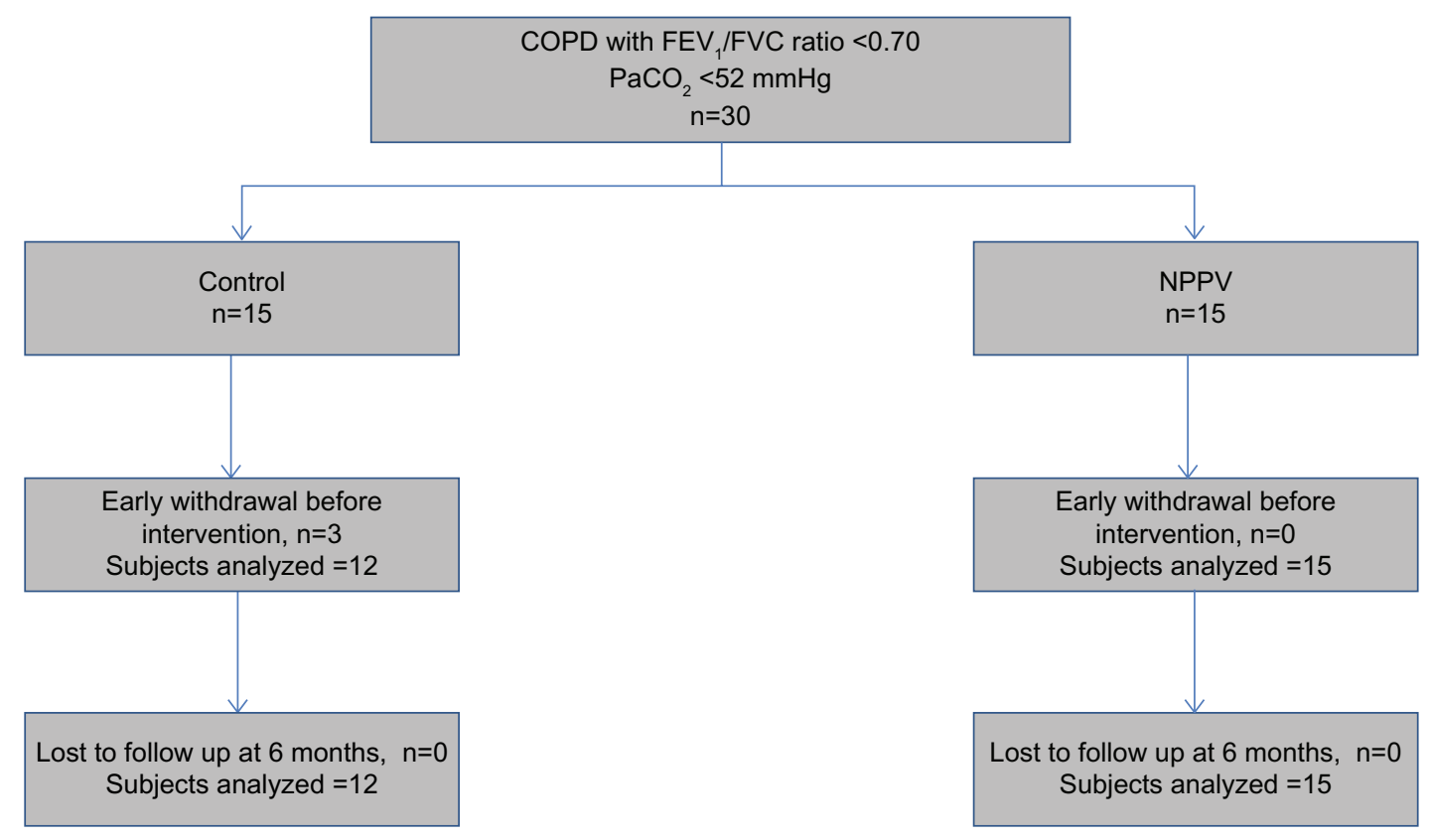

Figure I Randomization and follow-up of patients in intervention and control arms.

Abbreviations: COPD, chronic obstructive pulmonary disease; $\mathrm{FEV}_{1}$, forced expiratory volume in the first second; $\mathrm{FVC}$, forced vital capacity; PaCO ${ }_{2}$, partial pressure of carbon dioxide in arterial blood; NPPV, noninvasive positive pressure ventilation. 
Table I Comparison of baseline characteristics in cases and controls

\begin{tabular}{|c|c|c|}
\hline Variable & NPPV $(n=15)$ & Controls $(n=12)$ \\
\hline Age (years) ${ }^{\dagger}$ & $70(66-73)$ & $68(65-78)$ \\
\hline Sex (\% male) & $8(53)$ & $12(100)^{*}$ \\
\hline BMI $\left(\mathrm{kg} / \mathrm{m}^{2}\right)$ & $24.8(2.8)$ & $24.8(4.8)$ \\
\hline Pack-years of smoking & $59(29)$ & $61(30)$ \\
\hline FEV $\%$ pred & $30.3(7)$ & $29.6(7.4)$ \\
\hline FVC \%pred & $68.8(14.1)$ & $59.4(8)$ \\
\hline $\mathrm{NIF}\left(\mathrm{cm} \mathrm{H} \mathrm{H}_{2} \mathrm{O}\right)$ & $-48.9(14.5)$ & $-63.2(23.9)$ \\
\hline $\mathrm{PaCO}_{2}(\mathrm{mmHg})$ & $42.4(5.6)$ & $41.9(4.6)$ \\
\hline $\mathrm{PaO}_{2}(\mathrm{mmHg})$ & $65.1(13.3)$ & $73.9(9.9)$ \\
\hline 6MWD (m) & $284(101)$ & 321 (91) \\
\hline \multicolumn{3}{|l|}{ CRQ score } \\
\hline Dyspnea & $3.8(I)$ & $3.7(I)$ \\
\hline Fatigue & $4.3(1)$ & $4.1(1)$ \\
\hline Emotional function & $5.5(0.7)$ & $5.3(1.1)$ \\
\hline Mastery & $5(1.1)$ & $5.3(1.4)$ \\
\hline \multicolumn{3}{|l|}{ Dyspnea } \\
\hline TDI-Function & $1.9(0.7)$ & I.5 (0.7) \\
\hline TDI-Task & $1.3(0.5)$ & $\mathrm{I} .4(0.7)$ \\
\hline TDI-Effort & $1.3(0.5)$ & $1.3(0.5)$ \\
\hline TDI total & $4.5(1.6)$ & $4.2(1.5)$ \\
\hline PSQI & $3.7(3)$ & $6.1(3.2)$ \\
\hline
\end{tabular}

Notes: All results are expressed as the mean (standard deviation) except for ${ }^{\dagger}$ median (interquartile range). $* P<0.05$

Abbreviations: $\mathrm{FEV}_{1}$, forced expiratory volume in the first second; \%pred, percent predicted; FVC, forced vital capacity; NIF, negative inspiratory force; NPPV, noninvasive positive pressure ventilation; $\mathrm{PaCO}_{2}$, partial pressure of carbon dioxide in arterial blood; $\mathrm{PaO}_{2}$, partial pressure of oxygen in arterial blood; 6MWD, sixminute walk distance; CRQ, Chronic Respiratory Disease Questionnaire; TDI, Transitional Dyspnea Index at baseline; PSQI, Pittsburgh Sleep Quality Index; BMI, body mass index.

conservation of oxygen levels $(+2.1 \mathrm{mmHg}, P=0.02)$. There was a trend towards improvement in NIF (delta 7 with NPPV versus delta 0.3 in controls), but this did not reach statistical significance $(P=0.14)$. There was no change in $\mathrm{PaCO}_{2}$. There was also no improvement in six-minute walk distance. NPPV did not result in a change in $\mathrm{FEV}_{1}$. There was no difference in the number of exacerbations in either group during the period of the study, with one exacerbation in each group.

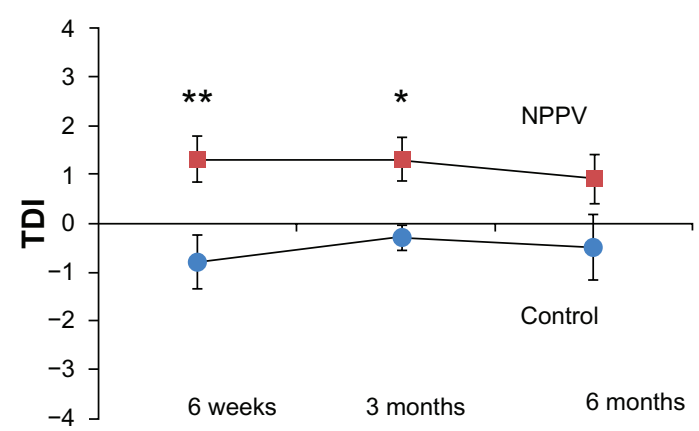

\section{Compliance and side effects}

The average duration of NPPV use per night was about 3.1 hours (Table 3). More than $40 \%$ used it for more than 4 hours per night. More than half $(8 / 15)$ used it for more than 4 hours in the first week (initial adopters). Of those using NPPV for more than 4 hours per night in the first week, 75\% used NPPV for a mean of more than 4 hours per night for the entirety of the study. Eighty-eight percent of initial adopters expressed interest in continuing use of NPPV beyond the duration of the study. Even though there were some adverse effects from using NPPV, these were minimal (Table 4). There was no change in the quality of sleep (Table 2). Overall, 53\% of subjects indicated a willingness to continue using NPPV beyond the period of the study. Interestingly, the improvement in CRQ-Mastery correlated significantly with the average number of hours of NPPV use (Spearman's $r=-0.83$, $P<0.001$, Figure 3). More side effects were reported by subjects in the NPPV arm, although this did not preclude them from continued use of the intervention (Table 4).

\section{Discussion}

We showed that there was a small improvement in some quality of life indices in patients with stable COPD administered NPPV for 6 months. There was a significant improvement in CRQ-Mastery and TDI-Task over time with application of NPPV. There was also a beneficial effect on $\mathrm{PaO}_{2}$.

The role of domiciliary nocturnal NPPV in the management of chronic stable COPD is controversial. The current literature is conflicting, but seems to favor its use in patients with hypercapnia, and with high intensity, targeting lowering $\mathrm{PaCO}_{2}$ levels. While multiple retrospective observational studies have shown a survival benefit for nocturnal NPPV in chronic stable hypercapnic COPD patients, ${ }^{5-7,20}$ these results have not been supported in randomized controlled trials. ${ }^{8-10}$ These, and other smaller studies, also found inconsistent

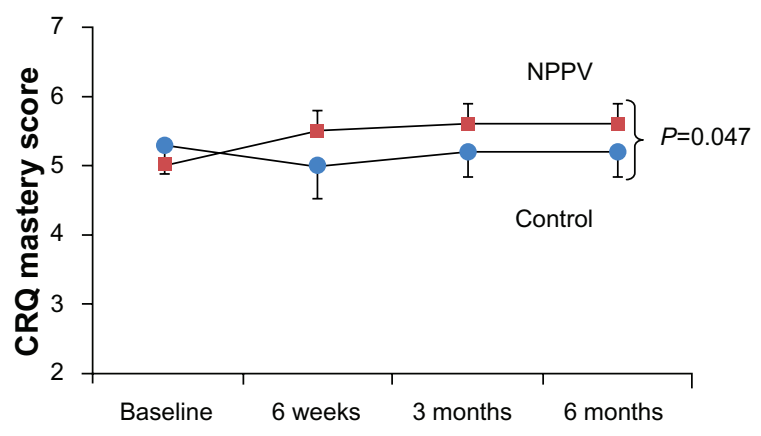

Figure 2 Change in dyspnea measured by TDI and quality of life (CRQ-Mastery domain) over time in intervention and control arms. Dots represent control arm; squares represent intervention arm.

Notes: $* P<0.05$ and $* * P<0.01$.

Abbreviations: TDI, Transitional Dyspnea Index; CRQ, Chronic Respiratory Disease Questionnaire; NPPV, noninvasive positive pressure ventilation. 
Table 2 Comparison of outcomes between intervention and control arms at 6 months

\begin{tabular}{|c|c|c|c|c|c|c|c|}
\hline & \multicolumn{3}{|c|}{$\operatorname{NPPV}(n=15)$} & \multicolumn{3}{|c|}{ Controls $(n=\mid 2)$} & \multirow[t]{2}{*}{$P$-value } \\
\hline & Baseline & 6 months & Difference & Baseline & 6 months & Difference & \\
\hline FEV , \%pred & $30.3(7)$ & $31.2(11.9)$ & 0.9 & $29.6(7.4)$ & $31(7.8)$ & 1.4 & 0.84 \\
\hline FVC \%pred & $68.8(14.1)$ & $71.9(16.7)$ & 3.1 & $59.4(8)$ & $60.8(30.2)$ & 1.3 & 0.74 \\
\hline $\mathrm{NIF}\left(\mathrm{cm} \mathrm{H} \mathrm{H}_{2} \mathrm{O}\right)$ & $-48.9(14.5)$ & $-55.9(20.3)$ & 7 & $-63.2(23.9)$ & $-63(21.9)$ & 0.3 & 0.14 \\
\hline $\mathrm{PaCO}_{2}(\mathrm{mmHg})$ & $42.4(5.6)$ & $44.3(8.5)$ & 1.9 & $41.9(4.6)$ & $42.9(4.5)$ & 1 & 0.68 \\
\hline $\mathrm{PaO}_{2}(\mathrm{mmHg})^{*}$ & $65.1(13.3)$ & $67.2(14.4)$ & 2.1 & $73.9(9.9)$ & $66.8(9.9)$ & -7.2 & 0.02 \\
\hline 6MWD (m) & $284(101)$ & $280(\mid 42)$ & -14 & $321(91)$ & 304 (I29) & -17 & 0.73 \\
\hline \multicolumn{8}{|l|}{ CRQ score } \\
\hline Dyspnea & $3.8(1)$ & $4.1(1.2)$ & 0.3 & $3.7(1)$ & $3.4(0.9)$ & -0.3 & 0.26 \\
\hline Fatigue & $4.3(I)$ & $4.6(1.3)$ & 0.4 & $4.1(1)$ & $4.2(0.9)$ & 0 & 0.36 \\
\hline Emotional function & $5.5(0.7)$ & $5.6(I . I)$ & 0.2 & $5.3(\mathrm{I} . \mathrm{I})$ & $5.3(\mathrm{I} .3)$ & 0 & 0.46 \\
\hline Mastery* & $5(I . I)$ & $5.6(I)$ & 0.6 & $5.3(1.4)$ & $5.2(1.2)$ & -0.1 & 0.04 \\
\hline \multicolumn{8}{|l|}{ Dyspnea } \\
\hline TDI-Function & $1.9(0.7)$ & $0(0.8)$ & -1.9 & I.5 (0.7) & $-0.2(0.7)$ & -1.7 & 0.63 \\
\hline TDI-Task* & I.3 (0.5) & $0.5(0.7)$ & -0.8 & I. $4(0.7)$ & $-0.3(0.7)$ & -1.8 & 0.03 \\
\hline TDI-Effort & I.3 $(0.5)$ & $0.5(0.7)$ & -0.8 & I.3 $(0.5)$ & $-0.3(0.7)$ & -1.6 & 0.06 \\
\hline TDI total & $4.5(1.6)$ & $0.9(2)$ & -3.4 & $4.2(1.5)$ & $-0.5(2.3)$ & -4.7 & 0.35 \\
\hline PSQI & $3.7(3)$ & $3.4(2.3)$ & 0.2 & $6.1(3.3)$ & $5.7(3.2)$ & 0.4 & 0.77 \\
\hline
\end{tabular}

Notes: All results are expressed as the mean (standard deviation). $* P<0.05$.

Abbreviations: $\mathrm{FEV}_{1}$, forced expiratory volume in the first second; \%pred, percent predicted; FVC, forced vital capacity; NIF, negative inspiratory force; PaCO, partial pressure of carbon dioxide in arterial blood; $\mathrm{PaO}_{2}$, partial pressure of oxygen in arterial blood; 6MWD, six-minute walk distance; CRQ, Chronic Respiratory disease Questionnaire; TDI, Transitional Dyspnea Index at baseline; PSQI, Pittsburgh Sleep Quality Index.

effects on sleep quality, quality of life, and dyspnea scores in hypercapnic COPD patients using NPPV. ${ }^{8-11,21-23}$ Most of these trials attempted to use varying intensity of NPPV to reduce daytime hypercapnia and improve gas exchange, and seemed to indicate that adequate lowering of $\mathrm{PaCO}_{2}$ and nocturnal hypoventilation was associated with the most benefits. ${ }^{24}$ It is possible that the inconsistent effects of NPPV were due to usage of low levels of pressure. Dreher et al showed in a short-duration study that high-intensity NPPV with controlled pressure can significantly reduce nocturnal $\mathrm{PaCO}_{2}$, improve dyspnea scores, lung function tests, and quality of life. ${ }^{25}$ Based on these, Medicare and Medicaid Services recommended a cutoff of $\geq 52 \mathrm{mmHg}$, in addition to other criteria, for initiating domiciliary nocturnal NPPV in stable hypercapnic patients. ${ }^{15}$ In contrast with these recommendations, we hypothesized that the inconsistent effects seen in previous studies might have been due to the intervention being late in the course of disease.

Table 3 Compliance with noninvasive positive pressure ventilation

\begin{tabular}{ll}
\hline Days used & $80.6(69 . \mathrm{I})$ \\
\% days used & $42(36)$ \\
Number of hours used (average per night), patient-reported & $3.9(3.4)$ \\
Number of hours used (average per night), machine-reported & $3.1(3.3)$ \\
$\%$ use greater than 4 hours per night & $40 \%$ \\
Initial compliance (usage $>4$ hours/night in first week) & $8(53 \%)$ \\
Number indicating willingness to continue using device (\%) & $8(53)$ \\
\hline Note: All numbers are expressed as the mean (standard deviation). &
\end{tabular}

In patients without hypercapnia, NPPV cannot be targeted toward $\mathrm{PaCO}_{2}$, but might still benefit patients by lowering the work of breathing. Although ours is the first study to target this group specifically, other studies did include subjects who had similar $\mathrm{PaCO}_{2}$ levels (Table 5). To our knowledge, no study has compared the effect of NPPV in normocapnic COPD with controls not undergoing another intervention such as rehabilitation and domiciliary oxygen that could confound the results.

NPPV use was associated with some minor benefits in our study in the domain of mastery, and in preservation of $\mathrm{PaO}_{2}$. This supports the results seen in two other shortduration studies aiming to recruit hypercapnic patients, but with $\mathrm{PaCO}_{2}$ levels comparable with our inclusion criteria. ${ }^{21,23}$ The difference in oxygenation levels was a surprising finding, and is most likely due to NPPV leading to redistribution of airflow toward areas of better perfusion, resulting in improve-

Table 4 Side effects

\begin{tabular}{lll}
\hline & NPPV $(\mathbf{n}=\mathbf{I} \mathbf{5})$ & Controls $(\mathbf{n}=\mathbf{I} \mathbf{2})$ \\
\hline Dryness of eyes & $\mathrm{I}(\mathrm{I})$ & $\mathrm{I}(0)$ \\
Sinus congestion & $5(2)$ & 0 \\
Nose bleeds & $\mathrm{I}(0)$ & $\mathrm{I}(0)$ \\
Discomfort & $5(3)$ & 0 \\
Skin breaks & $\mathrm{I}(\mathrm{I})$ & 0 \\
\hline
\end{tabular}

Notes: All numbers expressed as total number experiencing symptoms any time during course of study; numbers in brackets indicate those who had persistent symptoms at 6 months.

Abbreviation: NPPV, noninvasive positive pressure ventilation. 


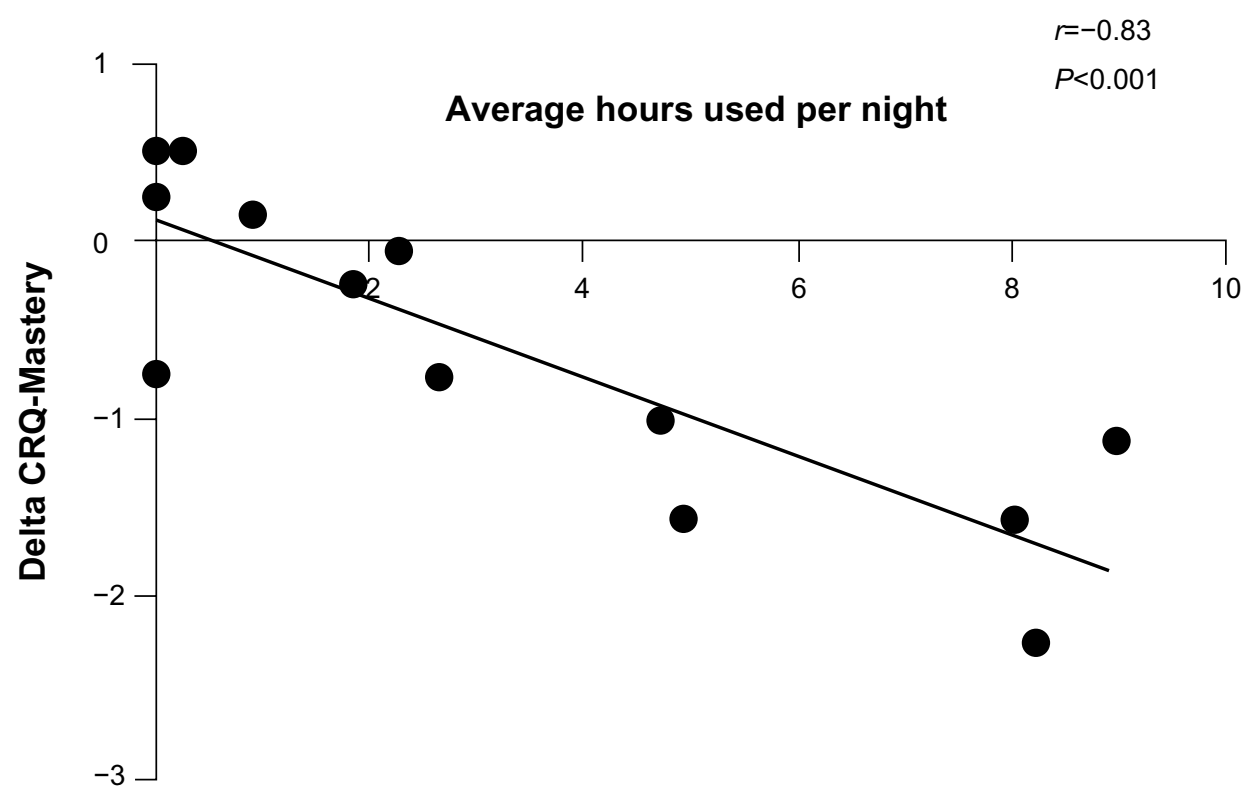

Figure 3 Correlation between change in CRQ-Mastery domain and average numbers of hours of use of noninvasive positive pressure ventilation. Abbreviation: CRQ, Chronic Respiratory Disease Questionnaire.

ment in ventilation/perfusion matching. ${ }^{26}$ Results from shortduration trials cannot be generalized because there can be a significant placebo effect from the mask, ${ }^{27}$ and there can also be significant problems with long-term compliance. ${ }^{28}$ A longer-duration randomized study by Casanova et al did not have $\mathrm{PaCO}_{2}$ level as an inclusion criterion but had a mean $\mathrm{PaCO}_{2}$ of $50.7 \mathrm{mmHg}$. In this study, there was a marginal improvement in Borg dyspnea score and in psychomotor coordination. ${ }^{8}$ Only the study by Garrod et al had $\mathrm{PaCO}_{2}$ levels comparable with those seen in our study. While they did show an improvement in exercise capacity, oxygenation, and CRQ, the study compared the effect of adding NPPV to an exercise program with exercise alone. ${ }^{11}$ We showed a change in some quality of life indices, but these were limited by the small number of subjects. In addition to baseline $\mathrm{PaCO}_{2}$ and improvement in hypoventilation, the other major factor that can affect study results is the intensity of NPPV used. Both these comparable randomized controlled studies used inspiratory and expiratory pressures similar to those used in the current study. ${ }^{8,11}$

Our study has a number of strengths. We studied a group of patients who were not significantly hypercapnic, which is the usual target group for this intervention. We excluded patients with sleep apnea because improvement in sleep can potentially result in improvement in quality of life scores, independent of COPD-related improvement. We meticulously assessed side

Table 5 Comparison of randomized studies of domiciliary NPPV in chronic stable COPD without hypercapnea

\begin{tabular}{|c|c|c|c|c|c|c|c|c|c|}
\hline & $\mathbf{n}$ & $\begin{array}{l}\text { Duration } \\
\text { of follow-up }\end{array}$ & $\begin{array}{l}\text { NPPV } \\
\text { intensity } \\
\left(\mathrm{cm} \mathrm{H}_{2} \mathrm{O}\right)\end{array}$ & $\begin{array}{l}\mathrm{PaCO}_{2} \\
(\mathrm{mmHg})\end{array}$ & Quality of life & Dyspnea & Sleep & Exacerbations & Survival \\
\hline $\begin{array}{l}\text { Garrod et al" } \\
\text { (versus } \\
\text { rehabilitation) }\end{array}$ & $\begin{array}{l}\text { Cases }(n=23) \\
\text { Controls } \\
(n=22)\end{array}$ & 8 weeks & $16 / 4$ & 44.2 & $\begin{array}{l}\text { CRQ } \\
\text { improved }\end{array}$ & $\begin{array}{l}\text { CRQ } \\
\text { dyspnea = } \\
\text { NS }\end{array}$ & - & - & - \\
\hline $\begin{array}{l}\text { Casanova et } \mathrm{al}^{8} \\
\text { (versus } \\
\text { domiciliary } \mathrm{O}_{2} \text { ) }\end{array}$ & $20(24)$ & One year & $12 / 4$ & 50.7 & $\begin{array}{l}\text { Improvement } \\
\text { in psychomotor } \\
\text { coordination }\end{array}$ & $\begin{array}{l}\text { Borg score } \\
\text { improved }\end{array}$ & - & NS & NS \\
\hline Lin et $\mathrm{al}^{23}$ & 12 (crossover) & 2 weeks & $\mid 2 /-$ & 50.5 & - & - & $\begin{array}{l}\text { Sleep } \\
\text { worsened }\end{array}$ & - & - \\
\hline Strumpf et $\mathrm{al}^{21}$ & 7 (crossover) & 3 months & $15 /-$ & 50 & - & NS & NS & - & - \\
\hline Current study & $15(12)$ & 6 months & $15 / 5$ & 42 & $\begin{array}{l}\text { CRQ-Mastery } \\
\text { improved }\end{array}$ & $\begin{array}{l}\text { TDI-Task } \\
\text { improved }\end{array}$ & NS & NS & - \\
\hline
\end{tabular}

Abbreviations: COPD, chronic obstructive pulmonary disease; NPPV, noninvasive positive pressure ventilation; $\mathrm{PaCO}_{2}$, partial pressure of carbon dioxide in arterial blood; CRQ, Chronic Respiratory Disease Questionnaire; $\mathrm{O}_{2}$, oxygen; TDI, Transitional Dyspnea Index; NS, no significant change. 
effects resulting from use of the NPPV mask. There were also some limitations to our study. We did not have a sham arm, and some of the results could be due to a placebo effect. The control subjects were all male, and while we are not aware of any gender differences in response to NPPV, this may have played a role. This study was underpowered to assess end points such as mortality or exacerbation frequency. However, those were not the main aims of our study. Compliance was low, probably due to lack of titration of pressures to each subject, lack of a run-in period, and the nature of the intervention. However, this is not unique to our study. ${ }^{11}$

In conclusion, use of NPPV is associated with minor improvements in $\mathrm{PaO}_{2}$ and the subdomains of quality of life and dyspnea indices. Whether attainment of the minimal clinically important difference of 0.5 for the mastery domain is worth the cost and inconvenience of NPPV can only be determined by each patient based on cost and tolerance. Nevertheless, this study found a significant difference in this domain. Based on this small study, NPPV has some benefit in COPD patients with $\mathrm{PaCO}_{2}<52 \mathrm{mmHg}$. Better compliance may be associated with improved outcome benefits in this group. Future large studies or meta-analyses in this group will clarify the utility of this intervention.

\section{Acknowledgments}

We extend our gratitude to the study subjects, to Charles Dayton for help with the institutional review board approval process, and to Bridget Zimmerman for statistical assistance.

\section{Author contributions}

SPB analyzed and interpreted the data, and wrote the manuscript. MWP and JSW contributed to the study conception and design, data collection, and revised the manuscript for important intellectual content. LD contributed to the study design, recruitment, data collection, data analyses, and interpretation and writing the manuscript. LD has full access to all data in the study and acts as the guarantor for accuracy of the manuscript.

\section{Disclosure}

The study was sponsored by Respironics Inc, which had no input in the design, data, or writing of the paper. Otherwise none of the authors have any conflicts of interest to declare.

\section{References}

1. [No authors listed]. Deaths from chronic obstructive pulmonary disease United States, 2000-2005. MMWR Morb Mortal Wkly Rep. 2008;57(45): $1229-1232$.
2. Catterall JR, Douglas NJ, Calverley PM, et al. Transient hypoxemia during sleep in chronic obstructive pulmonary disease is not a sleep apnea syndrome. Am Rev Respir Dis. 1983;128(1):24-29.

3. O’Donoghue FJ, Catcheside PG, Ellis EE, et al. Sleep hypoventilation in hypercapnic chronic obstructive pulmonary disease: prevalence and associated factors. Eur Respir J. 2003;21(6):977-984.

4. Keenan SP, Mehta S. Noninvasive ventilation for patients presenting with acute respiratory failure: the randomized controlled trials. Respir Care. 2009;54(1):116-126.

5. Jones SE, Packham S, Hebden M, Smith AP. Domiciliary nocturnal intermittent positive pressure ventilation in patients with respiratory failure due to severe COPD: long-term follow up and effect on survival. Thorax. 1998;53(6):495-498.

6. Budweiser S, Hitzl AP, Jorres RA, et al. Impact of noninvasive home ventilation on long-term survival in chronic hypercapnic COPD: a prospective observational study. Int J Clin Pract. 2007;61(9): 1516-1522.

7. Windisch W, Kostic S, Dreher M, Virchow JC Jr, Sorichter S. Outcome of patients with stable COPD receiving controlled noninvasive positive pressure ventilation aimed at a maximal reduction of $\mathrm{Pa}\left(\mathrm{CO}_{2}\right)$. Chest. 2005;128(2):657-662.

8. Casanova C, Celli BR, Tost L, et al. Long-term controlled trial of nocturnal nasal positive pressure ventilation in patients with severe COPD. Chest. 2000;118(6):1582-1590.

9. Clini E, Sturani C, Rossi A, et al. The Italian multicentre study on noninvasive ventilation in chronic obstructive pulmonary disease patients. Eur Respir J. 2002;20(3):529-538.

10. McEvoy RD, Pierce RJ, Hillman D, et al. Nocturnal non-invasive nasal ventilation in stable hypercapnic COPD: a randomised controlled trial. Thorax. 2009;64(7):561-566.

11. Garrod R, Mikelsons C, Paul EA, Wedzicha JA. Randomized controlled trial of domiciliary noninvasive positive pressure ventilation and physical training in severe chronic obstructive pulmonary disease. $\mathrm{Am}$ J Respir Crit Care Med. 2000;162(4 Pt 1):1335-1341.

12. University of Iowa. Trial of Non-invasive Ventilation for Stable COPD. Available from: http://clinicaltrials.gov/show/NCT01722773. NLM identifier: NCT01722773. Accessed October 24, 2013.

13. American Thoracic Society/European Respiratory Society Task Force. Standards for the Diagnosis and Management of Patients with COPD. Version 1.2. New York, NY: American Thoracic Society; 2004. Available from: http://www.thoracic.org/clinical/copd-guidelines/. Accessed October 18, 2013.

14. Netzer NC, Stoohs RA, Netzer CM, Clark K, Strohl KP. Using the Berlin Questionnaire to identify patients at risk for the sleep apnea syndrome. Ann Intern Med. 1999;131(7):485-491.

15. US Department of Health and Human Services, Center for Medicare and Medicaid Services. Durable medical equipment reference list. In: Medicare Coverage Issues Manual \$60.9. Baltimore, MD: CMS; 2002.

16. ATS Committee on Proficiency Standards for Clinical Pulmonary Function Laboratories. ATS statement: guidelines for the six-minute walk test. Am J Respir Crit Care Med. 2002;166(1):111-117.

17. Witek TJ Jr, Mahler DA. Minimal important difference of the transition dyspnoea index in a multinational clinical trial. Eur Respir J. 2003;21(2):267-272.

18. Guyatt GH, Berman LB, Townsend M, Pugsley SO, Chambers LW. A measure of quality of life for clinical trials in chronic lung disease. Thorax. 1987;42(10):773-778.

19. Buysse DJ, Reynolds CF 3rd, Monk TH, Berman SR, Kupfer DJ. The Pittsburgh Sleep Quality Index: a new instrument for psychiatric practice and research. Psychiatry Res. 1989;28(2):193-213.

20. Windisch W, Haenel M, Storre JH, Dreher M. High-intensity noninvasive positive pressure ventilation for stable hypercapnic COPD. Int J Med Sci. 2009;6(2):72-76.

21. Strumpf DA, Millman RP, Carlisle CC, et al. Nocturnal positivepressure ventilation via nasal mask in patients with severe chronic obstructive pulmonary disease. Am Rev Respir Dis. 1991;144(6): $1234-1239$. 
22. Meecham Jones DJ, Paul EA, Jones PW, Wedzicha JA. Nasal pressure support ventilation plus oxygen compared with oxygen therapy alone in hypercapnic COPD. Am J Respir Crit Care Med. 1995;152(2): $538-544$.

23. Lin CC. Comparison between nocturnal nasal positive pressure ventilation combined with oxygen therapy and oxygen monotherapy in patients with severe COPD. Am J Respir Crit Care Med. 1996;154(2 Pt 1): 353-358.

24. Wijkstra PJ. Non-invasive positive pressure ventilation (NIPPV) in stable patients with chronic obstructive pulmonary disease (COPD). Respir Med. 2003;97(10):1086-1093.

25. Dreher M, Storre JH, Schmoor C, Windisch W. High-intensity versus low-intensity non-invasive ventilation in patients with stable hypercapnic COPD: a randomised crossover trial. Thorax. 2010;65(4):303-308.
26. De Backer L, Vos W, Dieriks B, et al. The effects of long-term noninvasive ventilation in hypercapnic COPD patients: a randomized controlled pilot study. Int J Chron Obstruct Pulmon Dis. 2011;6:615-624.

27. Jenkinson C, Davies RJ, Mullins R, Stradling JR. Comparison of therapeutic and subtherapeutic nasal continuous positive airway pressure for obstructive sleep apnoea: a randomised prospective parallel trial. Lancet. 1999;353(9170):2100-2105.

28. Criner GJ, Brennan K, Travaline JM, Kreimer D. Efficacy and compliance with noninvasive positive pressure ventilation in patients with chronic respiratory failure. Chest. 1999;116(3):667-675. 


\section{Supplementary material}

Table SI Comparison between groups at each time point and over all time points (repeated-measures analysis of variance)

\begin{tabular}{|c|c|c|c|c|c|c|c|c|c|}
\hline & \multicolumn{2}{|l|}{ Baseline } & \multicolumn{2}{|l|}{6 weeks } & \multicolumn{2}{|l|}{3 months } & \multicolumn{2}{|l|}{6 months } & \multirow[t]{2}{*}{$P$-value } \\
\hline & NPPV & Controls & NPPV & Controls & NPPV & Controls & NPPV & Controls & \\
\hline FEV \%pred & $30.3(7)$ & $29.6(7.4)$ & & & $32.2(11.8)$ & 31.5 (6.4) & $31.2(11.9)$ & 31 (7.8) & 0.81 \\
\hline FVC \%pred & $68.8(14.1)$ & $59.4(8)$ & & & $74.2(19.2)$ & $62.8(8.8)$ & $71.9(16.7)$ & $60.8(30.2)$ & 0.97 \\
\hline $\mathrm{NIF}\left(\mathrm{cm} \mathrm{H}_{2} \mathrm{O}\right)$ & $-48.9(14.5)$ & $-63.2(23.9)$ & & & $-59.7(24.1)$ & $-64.5(23.9)$ & $-55.9(20.3)$ & $-63(21.9)$ & 0.16 \\
\hline $\mathrm{PaCO}_{2}(\mathrm{mmHg})$ & $42.4(5.6)$ & $41.9(4.6)$ & & & $44.1(7)$ & $42.7(4)$ & $44.3(8.5)$ & $42.9(4.5)$ & 0.92 \\
\hline $\mathrm{PaO}_{2}(\mathrm{mmHg})$ & $65.1(13.3)$ & $73.9(9.9)$ & & & $62.1(15.2)$ & $66.7(10.5)$ & $67.2(14.4)$ & $66.8(9.9)$ & 0.12 \\
\hline 6MWD (m) & $284(101)$ & $321(91)$ & $312(110)$ & $320(94)$ & $295(101)$ & $335(90)$ & $280(142)$ & 304 (I29) & 0.50 \\
\hline \multicolumn{10}{|l|}{ CRQ score } \\
\hline Dyspnea & $3.8(1)$ & $3.7(I)$ & $4.1(0.9)$ & $3.7(1.4)$ & $3.9(0.8)$ & $3.6(1.3)$ & 4.I (I.2) & $3.4(0.9)$ & 0.64 \\
\hline Fatigue & $4.3(1)$ & $4.1(1)$ & $4.5(0.9)$ & $3.9(1.2)$ & $4.4(I)$ & $4.1(1.1)$ & $4.6(1.3)$ & $4.2(0.9)$ & 0.39 \\
\hline Emotional function & $5.5(0.7)$ & $5.3(I . I)$ & $5.6(0.7)$ & $5 . I(I . I)$ & $5.5(0.9)$ & $5.2(\mathrm{I} .3)$ & $5.6(I . I)$ & $5.3(1.3)$ & 0.37 \\
\hline Mastery* & $5(1.1)$ & $5.3(1.4)$ & $5.5(1)$ & $5(1.6)$ & $5.6(I)$ & $5.2(1.2)$ & $5.6(I)$ & $5.2(1.2)$ & 0.047 \\
\hline \multicolumn{10}{|l|}{ Dyspnea } \\
\hline TDI-Function & $1.9(0.7)$ & I.5 (0.7) & $0.6(0.9)^{*}$ & $-0.3(I . I)$ & $0.4(0.8)^{*}$ & $-0.2(0.4)$ & $0(0.8)$ & $-0.2(0.7)$ & 0.31 \\
\hline TDI-Task & I.3(0.5) & I. $4(0.7)$ & $0.3(0.5)$ & $-0.3(0.6)$ & $0.4(0.5)^{*}$ & $-0.3(0.9)$ & $0.5(0.7)^{*}$ & $-0.3(0.7)$ & 0.07 \\
\hline TDI-Effort & I. $3(0.5)$ & I.3 (0.5) & $0.3(0.5)^{*}$ & $-0.3(0.6)$ & $0.4(0.5)^{*}$ & $-0.1(0.7)$ & $0.5(0.7)^{*}$ & $-0.3(0.7)$ & 0.13 \\
\hline TDI total & $4.5(1.6)$ & $4.2(\mathrm{I} .5)$ & $1.3(1.9)^{* *}$ & $-0.8(1.9)$ & I.3 (I.7)* & $-0.3(0.9)$ & $0.9(2)$ & $-0.5(2.3)$ & 0.28 \\
\hline
\end{tabular}

Notes: All results expressed as the mean (standard deviation). $* P<0.05$ and $* * P<0.01$.

Abbreviations: $\mathrm{FEV}_{1}$, forced expiratory volume in the first second; \%pred, percent predicted; FVC, forced vital capacity; NIF, negative inspiratory force; NPPV, noninvasive positive pressure ventilation; $\mathrm{PaCO}_{2}$, partial pressure of carbon dioxide in arterial blood; $\mathrm{PaO}_{2}$, partial pressure of oxygen in arterial blood; 6MWD, six-minute walk distance; CRQ, Chronic Respiratory Disease Questionnaire; TDI, Transitional Dyspnea Index at baseline.

\section{Publish your work in this journal}

The International Journal of COPD is an international, peer-reviewed journal of therapeutics and pharmacology focusing on concise rapid reporting of clinical studies and reviews in COPD. Special focus is given to the pathophysiological processes underlying the disease, intervention programs, patient focused education, and self management protocols.

\section{Dovepress}

This journal is indexed on PubMed Central, MedLine and CAS. The manuscript management system is completely online and includes a very quick and fair peer-review system, which is all easy to use. Visit http://www.dovepress.com/testimonials.php to read real quotes from published authors. 